REVIEW

\title{
Combination treatment strategies in early rheumatoid arthritis
}

E Suresh, C M Lambert

Ann Rheum Dis 2005;64:1252-1256. doi: 10.1136/ard.2004.032219

Combinations of disease modifying antirheumatic drugs (DMARDs) are increasingly being used in patients with early rheumatoid arthritis (RA) when long term results with sequential DMARD monotherapy are disappointing. Combination DMARD therapy may be more effective than monotherapy, and has no additional short term adverse events. The evidence for using combination DMARD therapy is still weak, however, and further trials are needed.

See end of article for authors' affiliations

Correspondence to: Dr E Suresh, Rheumatology Department, Kettering General Hospital, Rothwell Road, Kettering, Northants NN16 8UZ, UK;

dr_esuresh@hotmail.com

Accepted 23 April 2005 Published Online First 28 April 2005
$\mathrm{T}$ he optimal initial strategy for controlling disease in patients with rheumatoid arthritis (RA) remains elusive. Although the benefits of early treatment with disease modifying antirheumatic drugs (DMARDs) are indisputable, ${ }^{1-8}$ the order in which to use the various DMARDs and whether to use them singly or in combination is less certain. The traditional approach has been to use sequential DMARD monotherapy with substitution of an alternative DMARD when there is inadequate response or toxicity to the first DMARD, but long term studies have indicated several drawbacks with this strategy. ${ }^{9-12}$ Induction of sustained remission is seldom achieved. Individual DMARDs tend to be ineffective in a proportion of patients or lose their effectiveness with time. Only $5-15 \%$ of patients with RA maintain the initial response to a DMARD, with the exception of methotrexate and prednisolone, beyond 5 years. Also, prior DMARD use and longer duration of disease affect the likelihood of response to DMARD treatment, and subsequent DMARDs therefore tend not to be as effective as the first. ${ }^{2}$ Although disease progression is retarded to some extent with this approach, structural damage and functional decline progress while the "right" drug is sought. Thus, in recent years, there has been increased interest in using combination DMARD therapy for patients with early RA.

\section{PRINCIPLES BEHIND COMBINATION DMARD THERAPY}

The principle behind combination therapy is to combine drugs with different mechanisms of action to increase efficacy, while maintaining a favourable side effect/toxicity profile, analogous to the use of combination cytotoxic treatment in oncology. Different strategies in the use of combination therapy have individual merits and disadvantages. In the step-down approach, the most aggressive treatment is offered at a stage when the patient is likely to be most responsive to pharmacological measures. Once the disease is brought under control, the drugs with the least favourable toxicity profile are sequentially withdrawn and treatment is maintained with the agent with the best efficacy/ toxicity trade off. In the step-up approach, aggressive treatment is advocated only for a subset of patients not responding to monotherapy. Administration of multiple DMARDs can therefore be avoided in patients who would otherwise have responded well to a single agent. This approach also makes it easier to identify the offending agent when a new adverse event occurs.

\section{LESSONS LEARNT FROM EXISTING COMBINATION STUDIES}

Several lessons have been learnt from combination trials in general, and those performed in early RA in particular:

- Combination therapy improves clinical response, delays radiographic progression, improves functional outcome, and reduces work disability compared with monotherapy. ${ }^{13-25}$

- A step-down strategy may be better than a step-up strategy as it offers the best chance for rapid and effective suppression of inflammation.

There is limited evidence from the BeSt trial ${ }^{18}$ that patients with DMARD naive early "established" RA receiving "step-down" combination therapy, initially with either methotrexate, sulfasalazine, and prednisolone or methotrexate and infliximab have a better clinical response and radiological outcome than those who receive "sequential monotherapy" or step-up therapy.

- Corticosteroids and anti-tumour necrosis factor (TNF) drugs offer an attractive option as part of combination therapy for patients with early RA as they can rapidly suppress rheumatoid inflammation. ${ }^{13} 151726$

- Even short term use of aggressive combination therapy during the "early established" phase of RA, results in long term benefits compared with monotherapy.

The COBRA trial reported that patients who received early aggressive step-down combination

Abbreviations: $A C R$, American College of Rheumatology; DMARD, disease modifying antirheumatic drug; RA, rheumatoid arthritis; TNF, tumour necrosis factor 
therapy with methotrexate, sulfasalazine, and prednisolone for $<6$ months had less radiographic progression at 5 years than those who received sulfasalazine monotherapy. ${ }^{14}$ Five year results from the Fin-RA Co trial also reported reduced radiographic progression ${ }^{20}$ and reduced work disability ${ }^{21}$ among patients who received combination therapy with methotrexate, sulfasalazine, hydroxychloroquine, and prednisolone for the first 2 years compared with those who received sequential monotherapy. Treatment with infliximab and methotrexate has been shown to halt radiographic progression at 2 years compared with methotrexate monotherapy. ${ }^{17}$

- Combinations so far proved to be effective have mostly included corticosteroids or anti-TNF agents. ${ }^{13-21}$ Methotrexate has been the "anchor" drug in all successful combination trials.

Among the combinations that did not include either corticosteroids or anti-TNF, triple therapy with methotrexate, sulfasalazine, and hydroxychloroquine ${ }^{23}$ and step-up therapy with methotrexate, sulfasalazine, and ciclosporin ${ }^{22}$ have been shown to be effective. Triple therapy with methotrexate, sulfasalazine, and hydroxychloroquine has also been shown to be effective in two separate studies among patients with established RA. ${ }^{27} 28$

- Although it was previously thought that combination therapy was more toxic, ${ }^{29}$ more recent large, well designed randomised controlled trials have shown that this may not be true.

Despite these positive results, the available evidence is still insufficient to recommend use of combination DMARD therapy for all patients with early RA. The gaps in existing knowledge on combination treatment in early RA are mainly due to several shortcomings in existing combination studies. These shortcomings are discussed in the rest of this article and future research directions are suggested.

\section{GAPS IN CURRENT KNOWLEDGE AND DIRECTIONS FOR FUTURE RESEARCH Timing of treatment}

All "early RA" combination trials have based their definition of early RA on duration of symptoms (maximum symptom duration of up to 3 years), and recruited only those patients who met American College of Rheumatology (ACR) criteria for RA. ${ }^{30}$ The ACR criteria were developed only to separate patients with established RA from those with other musculoskeletal conditions, and do not perform well in early disease. $^{31}$ Moreover, most patients recruited to early RA combination trials had plain radiographic evidence of erosive changes at baseline. Thus, currently available evidence on combination therapy in early RA only relates to patients with early "established" RA.

There are several reasons why it would be useful to study the role of combination therapy in patients with "very early" RA. Firstly, several studies have shown that early DMARD treatment in RA leads to better medium and long term clinical, radiological, and functional outcome $e^{562-34}$ and that a delay of even as little as $8-9$ months can result in detrimental long term outcome. ${ }^{35}{ }^{36}$ Longitudinal observational data from the Norfolk Arthritis Register (NOAR) have shown that radiological and functional disability outcome in patients who receive a DMARD within 6 months of symptom onset is similar to that of patients who do not need treatment with a DMARD. ${ }^{56}$ A recent study reported that $60 \%$ of patients who started DMARD treatment after a median disease duration of 3 months achieved an ACR50 response at 3 years compared with $25 \%$ of those who started DMARD treatment after a median disease duration of 12 months. ${ }^{8}$ Although our belief that the biology of the disease may be fundamentally altered by starting DMARD treatment during the very early phase of RA before the disease becomes persistent has not been substantiated through well designed randomised controlled trials, the sooner the DMARD is started the better.

Secondly, as discussed above, there is evidence that even short term use of aggressive combination therapy during the early established phase results in long term benefits (reduced radiographic progression and improved work disability) compared with monotherapy..$^{14} 172021$

Thirdly, although the benefits of early intervention have been established without doubt, none of the early or very early RA trials have reported significant remission. This is far from ideal, especially as the focus in recent years has shifted from simply controlling disease manifestations or retarding disease progression to complete suppression of synovitis and total prevention of damage. In other words, we should aim for complete remission and no longer be satisfied with an ACR20 or ACR50 response. It follows that there is an urgent need to study the role of combination therapy among patients with very early RA on the basis of available data favouring (very) early over delayed introduction of DMARD therapy, and data suggesting long term benefits with short term use of combination DMARD therapy during the early established phase of RA.

\section{"Complete remission of RA should be our aim and combination treatment should be tested among patients with very early $\mathrm{RA}^{\prime \prime}$}

How do we select patients with "very early" RA? Among various factors that predict persistence (or in other words, progression to RA) among patients with early, undifferentiated inflammatory arthritis, symptom duration lasting more than 12 weeks, presence of rheumatoid factor, or anti-cyclic citrullinated peptide antibody and radiographic erosions seem to be the most important. ${ }^{37-40}$ Thus, future trials should also include patients with persistent polyarthritis lasting more than 12 weeks (provided that other specific causes such as postviral arthritis have been excluded) as treatment of such patients with a DMARD is started in practice. ${ }^{41}$ Prediction models for self limiting, persistent erosive and persistent non-erosive disease have been developed, but they require further validation. ${ }^{40}$

\section{Optimal initial strategy}

Although the benefits of combination therapy are emerging, we still do not know if it is appropriate for all patients with early RA. It is unclear if it would be better to use blanket treatment with a combination of drugs in all patients or whether the use of aggressive treatment should be restricted to patients with suboptimal response to monotherapy.

\section{"The efficacy of various strategies should be tested among patients with early RA to identify the optimal initial strategy"}

For example, although the combination of infliximab and methotrexate has been shown to better than methotrexate monotherapy, ${ }^{17}$ it is not known if it is best to use this combination in all patients with early RA at the outset or whether anti-TNF drugs should only be added for patients with suboptimal response to methotrexate. None of the existing trials (with the exception of the BeSt trial ${ }^{18}$ ) have compared the different strategies, and most of the current evidence on combination therapy in early RA relates to trials 
that compared different combinations of disease modifying drugs with monotherapy. Although trials to test the various possible combinations are needed to identify the ones with the best efficacy/toxicity trade off, it is more important to test the efficacy of various strategies to identify the optimal initial strategy.

As discussed above, corticosteroids or anti-TNF drugs are likely to be included as part of a step-down strategy as they offer the best chance for rapid and effective suppression of inflammation. However, long term use of corticosteroids is inappropriate in view of their side effects. Worries about long term safety and lack of cost effectiveness would also preclude indefinite use of anti-TNF agents. Thus, even if combination therapy were to be used as the initial treatment in all patients, optimal maintenance regimens are currently unknown. Methotrexate might be a good choice as it has a higher long term retention than other disease modifying drugs. ${ }^{42}$ Also, limited evidence suggests that methotrexate may be better than ciclosporin as a maintenance agent. ${ }^{43}$

\section{Choice of individual drugs in the combination}

Several gaps remain about the optimum choice of individual components in the combination. Firstly, we now know that step-down regimens should probably include corticosteroids or anti-TNF agents as they offer the best chance of remission, but it is not known which of those two would offer the best results. Thus, a trial comparing induction treatment with these two agents would be useful. Secondly, the optimal dose of corticosteroids to be used is also not known as both low ${ }^{15}$ and high doses ${ }^{13}$ of corticosteroids have been shown to retard radiographic progression. Thirdly, it is unclear if the different strategies would work best with a certain combination of drugs. Fourthly, although leflunomide and methotrexate have been shown to be equally efficacious, ${ }^{44}$ leflunomide has never been studied among patients with early RA. Finally, earlier combination trials did not use DMARDs in adequate doses, possibly for fear of inducing side effects. For example, a modest $7.5 \mathrm{mg} /$ week of MTX was used in the COBRA trial, and it was discontinued very early (after week 28) in all patients. ${ }^{13}$ Although more recent trials have pushed the dose of individual drugs in the combination to the maximum recommended, parenteral methotrexate, which has a bioavailability of $100 \%$, has never been tested. ${ }^{45}$

\section{"Advances in pharmacogenetics should help in the choice of DMARDs for combination therapy"}

The choice of individual drugs in the combination has been empirical and partly extrapolated from combination studies in established RA. The usefulness of most DMARDs in RA was discovered by chance, and their mechanisms of action are not fully understood ${ }^{46}$ It is therefore difficult to make a completely rational decision when choosing individual drugs for the combination. As far as possible, drugs are combined based on current knowledge of mechanisms of action, pharmacokinetics, efficacy, and toxicity. ${ }^{47}$ Thus, combining methotrexate and leflunomide may be synergistic as the former inhibits purine metabolism, while the latter inhibits pyrimidine metabolism. Both methotrexate and azathioprine inhibit purine metabolic pathways, and hence may not be a rational combination. Other combinations such as methotrexate and ciclosporin might be synergistic in view of a positive pharmacokinetic interaction (ciclosporin reduces renal excretion of methotrexate). Recent advances in understanding the pharmacogenetics of disease modifying drugs may pave the way for more rational combinations in future. ${ }^{48}$

The "tight control of rheumatoid arthritis" (TICORA) study took a different approach and demonstrated that using conventional agents more effectively may be more important than the actual drug chosen. ${ }^{49}$ Routine outpatient management was compared with an intensive strategy comprising regular objective assessments of disease activity for protocoldriven escalation of conventional treatment among patients with early RA. The remission rates were impressive: $65 \% \mathrm{v}$ $16 \%$ for intensive $v$ standard care, respectively. It is of course possible that some of this benefit might have resulted from the greater use of combinations of DMARDs and corticosteroids in the intensively treated group.

\section{Tailoring of treatment}

Although it is currently not known if different therapeutic strategies should be tailored according to prognosis, there is some evidence to suggest that combination therapy is appropriate for patients with early RA with poor prognostic factors. In a recent double blind trial, it was demonstrated that patients with early established RA with poor prognosis according to the Persistent Inflammatory Symmetrical Arthritis (PISA) scoring system, treated with infliximab and methotrexate combination therapy, had less radiographic progression at 1 year than those who were treated with methotrexate alone. The benefits were sustained at 2 years despite withdrawal of infliximab. ${ }^{50}$ In the COBRA trial, patients who received sulfasalazine monotherapy had more radiographic progression if they were positive for shared epitope than if they were negative for shared epitope. However, radiographic progression was similar among patients who received combination therapy irrespective of their shared epitope status. ${ }^{51}$ This might possibly be due to better responsiveness to combination therapy of patients who were shared epitope positive. The influence of shared epitope status on responsiveness to combination therapy has also been demonstrated among patients with late RA. ${ }^{52}$

Several factors have been proposed as bad prognostic factors in RA: high erythrocyte sedimentation rate or $\mathrm{C}$ reactive protein, presence and titre of rheumatoid factor and anti-cyclic citrullinated peptide antibody at baseline, the HLA-DRB I ${ }^{*} 4$ shared epitope allele (especially homozygotic), and early radiographic erosions. ${ }^{53}$ Prediction models that combine these factors have been developed, but have not been validated. A properly validated prediction model that could easily be used at the bedside and which would differentiate those patients with a benign outcome from those with a severe outcome is currently unavailable. The immediate need, therefore, is to develop and validate such a prediction model to stratify patients according to prognosis. This should then lead to studies to find out whether the most aggressive treatment should be targeted at patients who are likely to have a worse long term outcome.

\section{Trial design}

Trial design has been deficient in several trials. In general, the most conclusive evidence is derived from double blind, randomised controlled trials, but most existing early RA combination trials are open or single blind studies. There are some reasons why this strategy may not always be practical. In the trial by Proudman et al, in which patients with early RA were randomised to receive either aggressive combination therapy with methotrexate, ciclosporin, and intra-articular corticosteroids into all inflamed joints or sulfasalazine monotherapy, ${ }^{54}$ it might have been unethical to inject placebos into all inflamed joints. Also, double blinding is difficult when different strategies are compared, and when different routes (oral, subcutaneous, intravenous, etc) are employed to administer drugs. But on the whole, it would be unacceptable not to perform double blind studies while investigating a common disease such as RA.

Although there is a paucity of data on step-up treatment in early RA, several step-up trials have been performed among patients with late established RA. Most trials have studied 
Table 1 Important questions to be answered in future combination studies

- Can remission rates be improved if combination therapy is started during the "very early" phase?

- Should combination therapy be used first in all patients or only in a proportion of patients not responding to DMARD monotherapy?

- If combination therapy is used first, what is the optimal maintenance regimen?

- Is it best to use anti-TNF in all patients or only in patients with suboptimal response to methotrexate?

- Should corticosteroids be used in all patients? If so, should it be used in a high dose or low dose?

- What is the role of leflunomide in early RA?

- Would different strategies work best with one combination of drugs rather than another?

- Which subsets of patients would benefit the most from combination therapy? Should the most aggressive treatment be offered to patients who are likely to have a worse long term outcome?

patients with suboptimal response to methotrexate, and addition of leflunomide, ${ }^{55}$ ciclosporin, ${ }^{56}$ anti-TNF drugs, ${ }^{57}$ and triple therapy (sulfasalazine and hydroxychloroquine) ${ }^{58}$ has been shown to be beneficial compared with addition of placebo. A disadvantage of this design is that trial patients have already had a suboptimal response to one drug, and if combination therapy is shown to be beneficial, one can never be sure if the better response was due to the combination or whether it was solely due to the second drug that was added. ${ }^{59}$ Moreover, it might be unethical to add placebo to a drug to which the patient had had a suboptimal response. Thus, step-up trials should be designed such that if patients with suboptimal response to MTX are studied, they should be randomised to receive either MTX plus "active drug" or placebo plus "active drug".

Earlier trials mostly used fixed dose protocols, and the decision to change or intensify DMARD treatment was not driven by disease activity. For example, in the COBRA trial, ${ }^{13}$ prednisolone and methotrexate were both tapered after weeks 28 and 40, respectively, in all patients, irrespective of disease activity. Moreover, prednisolone was used at a fixed dose of $60 \mathrm{mg} /$ day (tapering to $7.5 \mathrm{mg} /$ day over 6 weeks) in all patients and not tailored according to disease activity. However, insight is changing over time and more recent trials have used protocols driven by disease activity.

\section{CONCLUSION}

Although combination therapy has been shown to be more effective than monotherapy, and to have no additional short term adverse events, there are several questions (table 1) that need to be answered through randomised controlled trials of adequate power. Current evidence on combination therapy is limited to patients with early established RA, and hence there is an urgent need to test various treatment strategies among patients with very early RA. As aggressive combination therapy (or even single drug therapy) is inappropriate for patients whose arthritis is likely to remit, a properly validated prediction model that could predict persistence among patients with early undifferentiated inflammatory arthritis would be helpful. RA is a chronic disease with a course measured in decades, and effective regimens to sustain therapeutic benefit over the longer term are needed. The optimal use of corticosteroids and anti-TNF drugs, and the role of leflunomide in early RA need to be defined. Finally, it is important to validate prognostic markers, and to determine if therapeutic strategies need to be tailored according to prognosis. Only with such further information will we know the optimal initial strategy for patients with early RA or RAlike polyarthritis.

\section{Authors' affiliations}

E Suresh, C M Lambert, Rheumatic Diseases Unit, Western General Hospital, Edinburgh, UK

\section{REFERENCES}

1 van der Heide A, Jacobs JW, Biilsma JW, Heurkens AH, van BoomaFrankfort C, van der Veen MJ, et al. The effectiveness of early treatment with second line anti-rheumatic drugs. A randomised controlled trial. Ann Intern Med 1996;124:699-707.

2 Anderson JJ, Wells G, Verhoeven AC, Felson DT. Factors predicting response to treatment in rheumatoid arthritis: the importance of disease duration. Arthritis Rheum 2000;43:22-9.

3 Egsmose C, Lung B, Borg G. Patients with RA benefit from early second-line therapy: 5-year follow-up of a prospective double-blind placebo-controlled study. J Rheumatol 1995;22:2208-13.

4 Tsakonas E, Fitzgerald AA, Fitzcharles MA, Cividino A, Thorne JC $M^{\prime}$ Seffar $A$, et al. Consequences of delayed therapy with second-line therapy in rheumatoid arthritis: a 3-year follow up on hydroxychloroquine in early rheumatoid arthritis (HERA) study. J Rheumatol 2000;27:623-9.

5 Bukhari MAS, Wiles NJ, Lunt BJ, Scott DGI, Symmons DPM, Silman AJ. Influence of disease modifying therapy on radiographic progression in inflammatory polyarthritis at five years. Arthritris Rheum 2003;48:46-53

6 Wiles NJ, Lunt M, Barrett EM, Bukhari M, Silman AJ, Symmons DP, et al. Reduced disability at 5 years with early treatment of inflammatory polyarthritis: results from a large observational cohort, using propensity models to adjust for disease severity. Arthritis Rheum 2001;44:1033-42.

7 Symmons DP, Jones MA, Scott DL, Prior P. Long term mortality outcome in RA: early presenters continue to do well. J Rheumatol 1998;25:1072-7.

8 Nell VPK, Machold KP, Eberl G, Stamm TA, Uffmann M, Smolen JS. Benefit of very early referral and very early therapy with disease-modifying antirheumatic drugs in patients with early rheumatoid arthritis. Rheumatology (Oxford) 2004;43:906-14

9 Wolfe F, Hawley DJ, Cathey MA. Termination of slow acting antirheumatic therapy in rheumatoid arthritis: a 14-year prospective evaluation of 1017 consecutive starts. J Rheumatol 1990;17:994-1002.

10 Pincus T, Marcum SB, Callahan LF. Long-term drug therapy for rheumatoid arthritis in seven rheumatology private practices: II. Second line drugs and prednisolone. J Rheumatol 1992;19:1885-94.

11 Aletaha D, Smolen JS. The rheumatoid arthritis patient in the clinic: comparing more than 1300 DMARD courses. Rheumatology (Oxford) 2002;41:1367-74.

12 Suarez-Almazor ME, Soskolne CL, Saunders LD, Russell AS. Use of second line drugs for the treatment of rheumatoid arthritis in Edmonton, Alberta. Patterns of prescription and long-term effectiveness. J Rheumatol 1995;22:836-43

13 Boers M, Verhoeven AC, Markusse HM, van de Laar MA, Westhovens R, van Denderen JC, et al. Randomised comparison of combined step-down prednisolone, methotrexate and sulphasalazine with sulphasalazine alone in early RA. Lancet 1997;350:309-18.

14 Landewe RBM, Boers $M$, Verhoeven AC, Westhovens R, van de Laar MA, Markusse HM, et al. COBRA combination therapy in patients with early RAlong term structural benefits of a brief intervention. Arthritis Rheum 2002;46:347-56

15 Kirwan JR. The effect of glucocorticoids on joint destruction in RA. N Eng/ J Med 1995;333: 142-6

16 Hickling P, Jacoby RK, Kirwan JR and the Arthritis and Rheumatism Low Dose Glucocorticosteroid Group. Joint destruction after glucocorticoids are withdrawn in early rheumatoid arthritis. Br J Rheumatol 1998;37:930-6.

17 St Clair EW, van der Heijde DM, Smolen JS, Maini RN, Bathon JM, Emery P, et al. Combination of infliximab and methotrexate therapy for early rheumatoid arthritis: a randomized, controlled trial. Arthritis Rheum 2004:50:3432-43.

18 De Vries-Bouwstra JK, Goekoop-Ruiterman YPM, Breedveld FC, Han KH, Kerstens PJS, Ronday HK, et al. Clinical and radiological outcomes after one year follow-up of the BeSt study, a randomised trialcomparing four different treatment strategies in early rheumatoid arthritis [abstract]. Arthritis Rheum 2003;48(suppl):LB18

19 Mottonen T, Hannonen P, Leirisalo-Repo M, Nissila M, Kautiainen H, Korpela $M$, et al. Comparison of combination therapy with single drug therapy in early RA. Lancet 1999;353:1568-73.

20 Korpela M, Laasonen L, Hannonen P, Kautiainen $\mathrm{H}$, Leirisalo- Repo M, Hakal $M$, et al. Retardation of joint damage in patients with early rheumatoid arthritis by initial aggressive treatment with disease modifying anti-rheumatic drugs. Arthritis Rheum 2004;50:2072-81.

21 Puolakka K, Kautiainen H, Mottonen T, Hannonen P, Korpela M, Julkunen H, et al. Impact of initial aggressive drug treatment with a combination of disease-modifying antirheumatic drugs on the development of work disability in early rheumatoid arthritis: a five-year randomized followup trial. Arthritis Rheum 2004;50:55-62.

22 Ferraccioli GF, Gremese E, Tomietto P, Favret G, Damato R, Di Poi E. Analysis of improvements, full responses, remission and toxicity in rheumatoid patients treated with step-up combination therapy (methotrexate, cyclosporin A, sulphasalazine) or monotherapy for three years. Rheumatology (Oxford) 2002;41:892-8.

23 Calguneri M, Pay S, Caliskaner Z, Apras S, Kiraz S, Ertenli I, et al. Combination therapy versus monotherapy for the treatment of patients with rheumatoid arthritis. Clin Exp Rheumatol 1999;17:699-704.

24 Gerards AH, Landewe RB, Prins AP, Bruyn GA, Goei The HS, Laan RF, et al. Cyclosporin A monotherapy versus cyclosporin $A$ and methotrexate 
combination therapy in patients with early rheumatoid arthritis: a double blind randomised placebo controlled trial. Ann Rheum Dis 2003;62:291-6.

25 Marchesoni A, Battafarano N, Arreghini M, Panni B, Gallazi M, Tosi S. Radiographic progression in early rheumatoid arthritis: a 12-month randomised controlled study comparing the combination of cyclosporin and methotrexate with methotrexate alone. Rheumatology (Oxford) 2003;42:1545-9.

26 Genovese MC, Bathon JM, Martin RW, Fleischmann RM, Tesser JR, Schiff MH, et al. Etanercept versus methotrexate in patients with early rheumatoid arthritis: two-year radiographic and clinical outcomes. Arthritis Rheum 2002;46: 1443-50.

27 O'Dell JR, Leff R, Paulsen G, Haire C, Mallek J, Eckhoff PJ, et al. Treatment of rheumatoid arthritis with methotrexate and hydroxychloroquine, methotrexate and sulfasalazine, or a combination of the three medications: results of a twoyear, randomized, double-blind, placebo-controlled trial. Arthritis Rheum 2002;46:1164-70.

28 O'Dell JR, Haire CE, Erikson N, Drymalski W, Palmer W, Eckhoff PJ, et al. Treatment of rheumatoid arthritis with methotrexate alone, sulfasalazine and hydroxychloroquine, or a combination of all three medications. N Engl J Med 1996;334:1287-91

29 Felson DT, Anderson JJ, Meenan RF. The efficacy and toxicity of combination therapy in rheumatoid arthritis. A meta-analysis. Arthritis Rheum 1994;37:1487-91.

30 Arnett FC, Edworthy SM, Bloch DA, McShane DJ, Fries JF, Cooper NS, et al. The American Rheumatism association 1987 revised criteria for the classification of rheumatoid arthritis. Arthritis Rheum 1988;31:315-24.

31 Dugowson CE, Nelson JL, Koepsell TD. Evaluation of the 1987 revised criteria for rheumatoid arthritis in a cohort of newly diagnosed female patients. Arthritis Rheum 1990;33:1042-6.

32 van der Heide A, Jacobs JW, Bijlsma JW, Heurkens AH, van BoomaFrankfort C, van der Veen MJ, et al. The effectiveness of early treatment with second line anti-rheumatic drugs. A randomised controlled trial. Ann Intern Med 1996;124:699-707.

33 Stenger AA, van Leeuwen MA, Houtman PM, Bruyn GA, Speerstra F, Barendsen $B C$, et al. Early effective suppression of inflammation in rheumatoid arthritis reduces radiographic progression. $\mathrm{Br} J$ Rheumatol 1998:37:1157-63.

34 Munro R, Hampson R, McEntegart A, Thomson EA, Madhok R, Capell H. Improved functional outcome in patients with early rheumatoid arthritis treated with intramuscular gold: results of a five year prospective study. Ann Rheum Dis 1998;57:88-93.

35 Egsmose C, Lung B, Borg G. Patients with RA benefit from early second-line therapy: 5-year follow-up of a prospective double-blind placebo-controlled study. J Rheumatol 1995;22:2208-13.

36 Tsakonas E, Fitzgerald AA, Fitzcharles MA, Cividino A, Thorne JC, $M^{\prime}$ Seffar $A$, et al. Consequences of delayed therapy with second-line therapy in rheumatoid arthritis: a 3-year follow up on hydroxychloroquine in early rheumatoid arthritis (HERA) study. J Rheumatol 2000;27:623-9.

37 Green M, Marzo-Ortego H, McGonagle D, Wakefield R, Proudman S, Conaghan $\mathrm{P}$, et al. Persistence of mild, early inflammatory arthritis. Arthritis Rheum 1999;42:2184-8.

38 Tunn ED, Bacon PA. Differentiating persistent from self-limiting symmetrical synovitis in an early arthritis clinic. Br J Rheumatol 1993;32:97-103.

39 Woolf AD, Hall ND, Goulding NJ, Kantharia B, Maymo J, Evison G, et al. Predictors of the long-term outcome of early synovitis: A 5-year follow up study. Br J Rheumatol 1991;30:251-4.

40 Visser H, le Cessie S, Vos K, Breedveld FC, Hazes JMW. How to diagnose rheumatoid arthritis early? A prediction model for persistent (erosive) arthritis. Arthritis Rheum 2002;46:357-65

41 Aletaha D, Eberl G, Nell VP, Machold KP, Smolen JS. Practical progress in realisation of early diagnosis and treatment of patients with suspected rheumatoid arthritis: results from two matched questionnaires within three years. Ann Rheum Dis 2002;61:630-4.
42 Yazici Y, Sokka T, Kautiainen H, Swearingen C, Kulman I, Pincus T. Long term safety of methotrexate in routine clinical care: discontinuation is unusual and rarely the result of laboratory abnormalities. Ann Rheum Dis 2005:64:207-11.

43 Marchesoni A, Battafarano N, Arreghini M, Pellerito R, Cagnoli M, Prudente $P$, et al. Step down approach using either cyclosporin $A$ or methotrexate as maintenance therapy in early rheumatoid arthritis. Arthritis Rheum 2002:47:59-66.

44 Emery P, Breedveld FC, Lemmel EM, Kaltwasser JP, Dawes PT, Gomor B, et al. A comparison of the efficacy and safety of leflunomide and methotrexate for the treatment of rheumatoid arthritis. Rheumatology (Oxford) 2000;39:655-65.

45 Jundt JW, Browne BA, Fiocco GP, Steele AD, Mock D. A comparison of low dose methotrexate bioavailability: oral solution, oral tablet, subcutaneous and intramuscular dosing. J Rheumatol 1993;20:1845-9.

46 Choy E, Panayi G. Mechanisms of action of second line agents and choice of drugs in combination therapy. Clin Exp Rheumatol 1990;18(suppl 17):20-8.

47 Furst DE. Clinical pharmacology of combination DMARD therapy in rheumatoid arthritis. J Rheumatol 1996;23(suppl 44):86-90.

48 Tanaka E, Taniguchi A, Urano W, Yamanaka H, Kamatani N Pharmacogenetics of disease-modifying anti-rheumatic drugs. Best Pract Res Clin Rheumatol 2004; 18:233-47.

49 Grigor C, Capell H, Stirling A, McMahon D, Lock P, Vallance R, et al. Effect of a treatment strategy of tight control for rheumatoid arthritis (the TICORA study): a single-blind randomised controlled trial. Lancet 2004;364:263-9.

50 Quinn MA, Conaghan PG, O'Connor PJ, Karim Z, Greenstein A, Brown A, et al. Very early treatment with infliximab in addition to methotrexate in early, poor-prognosis rheumatoid arthritis reduces magnetic resonance imaging evidence of synovitis and damage, with sustained benefit after infliximab withdrawal: results from a twelve-month randomized, double-blind, placebocontrolled trial. Arthritis Rheum 2005;52:27-35.

51 Lard LR, Boers M, Verhoeven A, Vos K, Visser H, Hazes JM, et al. Early and aggressive treatment of rheumatoid arthritis patients affects the association of HLA class II antigens with progression of joint damage. Arthritis Rheum 2002:46:899-905.

52 O'Dell JR, Nepom BS, Haire C, Gersuk VH, Gaur L, Moore GF, et al. HLADRB 1 typing in rheumatoid arthritis: predicting response to specific treatments. Ann Rheum Dis 1998:57:209-13.

53 Morel J, Combe B. How to predict prognosis in early rheumatoid arthritis. Best Pract Res Clin Rheumatol 2005;19:137-46.

54 Proudman SM, Conaghan PG, Richardson C, Griffiths B, Green MJ, McGonagle $D$, et al. Treatment of poor prognosis early RA: A randomised study of treatment with methotrexate, cyclosporin A and intraarticular corticosteroids compared with sulphasalazine alone. Arthritis Rheum 2000;43:1809-19.

55 Kremer JM, Genovese MC, Cannon GW, Caldwell JR, Cush JJ, Furst DE, et al. Concomitant leflunomide therapy in patients with active rheumatoid arthritis despite stable doses of methotrexate. A randomized, double-blind, placebocontrolled trial. Ann Intern Med 2002;137:726-33.

56 Tugwell P, Pincus T, Yocum D, Stein M, Gluck O, Kraag G, et al. Combination therapy with cyclosporine and methotrexate in severe rheumatoid arthritis. The Methotrexate-Cyclosporine Combination Study Group. N Engl J Med 1995;333:137-41.

57 Kremer JM, Weinblatt ME, Bankhurst AD, Bulpitt KJ, Fleischmann RM, Jackson CG, et al. Etanercept added to background methotrexate therapy in patients with rheumatoid arthritis: continued observations. Arthritis Rheum 2003;48: 1493-9

58 O'Dell JR, Haire C, Erikson N, Drymalski W, Palmer W, Maloley P, et al. Efficacy of triple DMARD therapy in patients with RA with suboptimal response to methotrexate. J Rheumatol Supp/ 1996:44:72-4.

59 Boers M. Add-on or step-up trials for new drug development in rheumatoid arthritis: a new standard? Arthritis Rheum 2003;48:1481-3. 